\title{
Targeted Preoperative Autologous Blood Donation in Total Knee Arthroplasty Reduces the Need for Postoperative Transfusion
}

\author{
Jad Bou Monsef, MD • Johannes Buckup, MD • David Mayman, MD • Robert Marx, MD • Amar Ranawat, MD • \\ Friedrich Boettner, MD
}

Received: 26 March 2013/Accepted: 26 June 2013 / Published online: 16 August 2013

(C) The Author(s) 2013. This article is published with open access at Springerlink.com

\begin{abstract}
Background: Preoperative donation of autologous blood has been widely used to minimize the potential risk of allogeneic transfusions in total knee arthroplasty. A previous study from our center revealed that preoperative autologous donation reduces the allogeneic blood exposure for anemic patients but has no effect for non-anemic patients. Questions/Purposes: The current study investigates the impact of a targeted blood donation protocol on overall transfusion rates and the incidence of allogeneic blood transfusions. Methods: Prospectively, 372 patients undergoing 425 unilateral primary knee replacements were preoperatively screened by the Blood Preservation Center between 2009 and 2012. Anemic patients with a hemoglobin level less than $13.5 \mathrm{~g} / \mathrm{dL}$ were advised to donate blood, while non-anemic patients did not donate. Results: Non-anemic patients who did not donate blood required allogeneic blood transfusions in $5.9 \%$ of the patients. The overall rate of allogeneic transfusion was significantly lower for anemic patients who donated autologous blood (group A, 9\%) than those who did not donate (group B, 33\%; $p<0.001$ ). Donating autologous blood did increase the overall transfusion rate of anemic patients to 0.84 per patient in group A compared to 0.41 per patient in group B $(p<0.001)$. Conclusion: This investigation confirms that abandoning preoperative autologous
\end{abstract}

Level of Evidence: Therapeutic Study Level II. See Levels of Evidence for a complete description.

This work was performed at the Hospital for Special Surgery, New York, NY.

Electronic supplementary material The online version of this article (doi:10.1007/s11420-013-9346-8) contains supplementary material, which is available to authorized users.

J. Bou Monsef, MD $\cdot$ J. Buckup, MD $\cdot$ D. Mayman, MD

R. Marx, MD · A. Ranawat, MD · F. Boettner, MD $(\bowtie)$

Hospital for Special Surgery,

535 East 70th Street,

New York, NY 10021, USA

e-mail: boettnerf@hss.edu blood donation for non-anemic patients does not increase allogeneic blood transfusion rates but significantly lowers overall transfusion rates.

Keywords anemia total knee arthroplasty. blood management - preoperative autologous blood donation . allogeneic transfusion

\section{Introduction}

Total knee arthroplasty (TKA) is one of the most common orthopedic procedures [14]. Improvements in the surgical technique over the last four decades have significantly decreased blood loss and transfusion requirements [21]. However, patients undergoing TKA are still at risk for allogeneic blood transfusions. Inherent risks of such transfusions persist despite improvement in safety and management of allogeneic blood and range from transfusion reactions and immunomodulation to the less common but more serious risk of contamination and viral disease transmission [8, 22]. In addition, allogeneic blood has been associated with increased incidence of surgical site infections [2, 18] as well as longer hospital stay [23]. The preoperative hemoglobin $(\mathrm{Hb})$ level is the most important factor determining transfusion risk $[10,13]$.

One of the safest methods to minimize exposure to allogeneic blood transfusions is preoperative autologous blood donation (PABD) [12] which is currently considered the standard of care in TKA [17].

However, autologous blood donation is associated with increased overall transfusion rates (autologous and allogeneic) $[6,9,12]$ and wastage rates up to $50 \%$ and its efficacy has been questioned in the more recent literature $[2,16]$. A previous study revealed that the reduction in allogeneic transfusions associated with PABD was confined to patients with baseline hemoglobin less than $12.5 \mathrm{~g} / \mathrm{dL}$. Non-anemic patients rarely required transfusions, leading to higher costs and numbers of units wasted [5]. Based on these data, 
targeted autologous blood donation based on preoperative hemoglobin was introduced at the authors' institution.

The current study investigates (1) the impact of targeted blood donation on overall transfusion rates, (2) the incidence of allogeneic blood transfusion in non-anemic patients when preoperative donation is abandoned, and (3) the efficacy of autologous blood donation in reducing the need for allogeneic blood in anemic patients.

\section{Methods}

Patients who underwent unilateral knee arthroplasty between 2009 and 2012 were preoperatively screened by the Blood Preservation Center as part of a prospective cohort study. Enrollment into the Blood Preservation Center was done through the individual private offices of four surgeons at the authors' institution. Patients were divided by preoperative hemoglobin level, utilizing $13.5 \mathrm{~g} / \mathrm{dL}$ as a cutoff. Patients with a hemoglobin level above $13.5 \mathrm{~g} / \mathrm{dL}$ were considered non-anemic and were not asked to donate blood prior to surgery. Anemic patients with a preoperative hemoglobin level less than $13.5 \mathrm{~g} / \mathrm{dL}$ were advised to donate 1 unit of autologous blood. Gender, age, BMI, preoperative $\mathrm{Hb}$, date of preoperative $\mathrm{Hb}$ measurement, date of autologous blood donation, number of autologous transfusions, number of allogeneic transfusions, time of transfusion, postoperative $\mathrm{Hb}$ levels until date of discharge, and in-house complications were recorded. Patients with bleeding disorders or other blood management interventions were excluded and patients whose actual blood management deviated from the standard protocol were analyzed as separate groups. The study was approved by the Institutional Review Board at the authors' institution.

Three hundred seventy-two patients underwent 425 primary total knee arthroplasty procedures during the study period. All procedures were performed under a tourniquet utilizing a standardized medial parapatellar approach with hypotensive spinal-epidural anesthesia. Seven non-anemic patients chose to predonate autologous blood and were excluded from the analysis and 135 anemic patients did not donate autologous blood and were analyzed as a separate group. Among the remaining 418 surgeries, 140 procedures were performed on males and 278 on females, with a mean age of 67 years at the time of the surgery (range, 3390 years) and BMI of $27 \mathrm{~kg} / \mathrm{m}^{2}$ (range, $13-43 \mathrm{~kg} / \mathrm{m}^{2}$ ) (Table 1).
Of $233(55 \%)$ TKA procedures performed in anemic patients, 98 donated 1 unit of autologous blood according to protocol (group A), while 135 did not donate any blood (group B). Out of 192 procedures performed on non-anemic patients, 185 followed protocol by not donating (group C). Autologous donation was done on average 10 days prior to the surgery and patients were given daily oral iron supplementation until the day of the surgery. Patients received allogeneic transfusions if their hemoglobin level dropped below $8.0 \mathrm{~g} / \mathrm{dL}$ and they displayed clinical symptoms of anemia (tachycardia and/or hypotension) despite an intravenous fluid bolus. The decision to transfuse autologous blood was made at the discretion of the anesthesiologist and medical attending and not according to a set threshold. All groups were similar in terms of age and BMI (Table 1 and Fig. 1).

Compared to the prior study, the cut off was moved from 12.5 to $13.5 \mathrm{~g} / \mathrm{dL}$ to reduce overall exposure to allogeneic blood. No patient with a hemoglobin level less than $10 \mathrm{~g} / \mathrm{dL}$ donated, and such patients usually have their procedures postponed until the anemia is investigated and treated. Data were analyzed using a standard two-tailed $t$ test (Microsoft Excel, Microsoft Corporation, Redmond, WA, USA, Microsoft Office Professional Plus 2010 Version 14.0.6 for Windows 7). A $p$ value of less than 0.05 was considered statistically significant. No patients elected to drop out of the study at any time (Table 1).

\section{Results}

Over the study period, 283 unilateral primary TKAs (67\%) were performed according to the protocol, 98 anemic patients who donated and 185 non-anemic patients who did not. Seventy-one percent of patients in the anemic group who donated blood (group A) received autologous transfusions (Table 2). The overall rate of allogeneic transfusion was significantly lower for anemic patients who donated autologous blood (group A, 9\%) than those who did not (group $\mathrm{B}, 33 \% ; p<0.001)$. The overall transfusion rate in group A was higher ( 0.84 per patient) than in group B (0.41 per patient; $p<0.001)$.

In the non-anemic group, the overall allogeneic transfusion rate was $5.9 \%$. Ninety percent of all allogeneic transfusions were given within $48 \mathrm{~h}$ of the surgery. No transfusion reactions were documented in any of the patients. No significant differences were detected in terms of length of stay or number of complications between the patient groups. No patient was

Table 1 Demographics of patients screened by the Blood Preservation Center

\begin{tabular}{|c|c|c|c|c|c|}
\hline & \multicolumn{2}{|c|}{ Anemic } & \multicolumn{2}{|c|}{ Non-anemic } & \multirow[t]{2}{*}{ Total } \\
\hline & PABD & No PABD & PABD & No PABD & \\
\hline Total number & 98 & 135 & 7 & 185 & 425 \\
\hline Male/female & $16 / 82$ & $19 / 116$ & $3 / 4$ & $105 / 80$ & $143 / 282$ \\
\hline Mean age in years (range) & $67.0(33-90)$ & $67.6(45-90)$ & $68.0(55-83)$ & $65.8(34-88)$ & $66.7(33-90)$ \\
\hline Mean BMI in $\mathrm{kg} \mathrm{m}^{-2}$ (range) & $26.3(14.7-43.4)$ & $25.8(12.8-47.7)$ & $33.6(19.0-73.6)$ & $27.7(16.1-45.6)$ & $26.9(12.8-73.6)$ \\
\hline
\end{tabular}




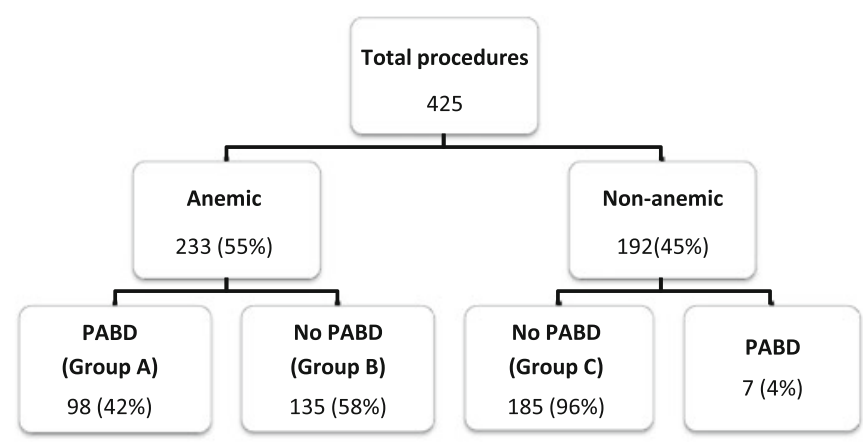

Fig. 1. Patient distribution by number of total knee arthroplasty procedures according to targeted PABD protocol.

readmitted for anemia, infection, or any thromboembolic events within a month of discharge (Table 2).

Discharge hemoglobin levels among anemic patients in the PABD group (group A) were $9.6 \mathrm{~g} / \mathrm{dL}$ (range, 8 to $11 \mathrm{~g} / \mathrm{dL}$ ), an average $2.4 \mathrm{~g} / \mathrm{dL}$ drop from preoperative levels. Similarly, patients in group $\mathrm{B}$ were discharged with a mean $\mathrm{Hb}$ of $9.5 \mathrm{~g} / \mathrm{dL}$, an average $2.9 \mathrm{~g} / \mathrm{dL}$ drop from the preoperative values $(p<0.001)$. Non-anemic patients on the other hand exhibited a mean $4.1 \mathrm{~g} / \mathrm{dL}$ drop in $\mathrm{Hb}$ to $10.6 \mathrm{~g} / \mathrm{dL}$ (range, 8.6 to $14.1 \mathrm{~g} / \mathrm{dL} ; p<0.001$ ) at the time of discharge.

\section{Discussion}

Although autologous blood shares some of the same risks as allogeneic blood transfusions, including fluid overload and clerical errors, it significantly decreases the risk of potentially serious adverse effects like viral disease transmission. In light of the high wastage rates, cost, and the significant increase of overall transfusion rates, the routine use of PABD has been questioned. The current study demonstrates the efficacy of a targeted preoperative autologous blood donation on preoperative hemoglobin levels.

The current study has a number of limitations. Patients who were excluded from the study might present a possible source of selection bias, namely the large number of anemic patients who did not donate autologous blood. Strict transfusion guidelines were only enforced for allogeneic blood transfusions, and autologous blood was transfused at the discretion of the covering anesthesiologist. Moreover, although the same surgical technique was used, the fact that multiple surgeons contributed to the patient series remains a possible source of bias. The procedures were performed under spinal epidural anesthesia which may limit the applicability of our results to centers utilizing general anesthesia and might increase overall transfusion requirements because of hypotensive hemodilution.

Preoperative autologous blood donation has an established role in decreasing allogeneic transfusion requirements [1, 17]. A Cochrane review showed a $68 \%$ reduction in exposure to allogeneic blood with the use of PABD at the expense of a $24 \%$ higher overall transfusion rate (allogeneic and/or autologous) [12]. The Orthopedic Surgery Transfusion Hemoglobin European Overview study investigated over 4,000 joint arthroplasty patients and also reported higher overall transfusion rates in patients donating autologous blood [19].

The correlation between preoperative hemoglobin levels and transfusion risk in joint arthroplasty is well established in the literature $[7,11,13,20]$. Patients with hemoglobin above $13 \mathrm{~g} / \mathrm{dL}$ have a transfusion risk five times lower than those with preoperative hemoglobin levels of 11 to $13 \mathrm{~g} / \mathrm{dL}$. Non-anemic patients also have the highest percentage of wasted autologous blood [15]. Keating et al. showed that routine autologous donation in patients with a hemoglobin greater than $13 \mathrm{~g} / \mathrm{dL}$ resulted in $66 \%$ of the autologous blood being wasted [13]. The benefit of PABD for non-anemic patients undergoing primary unilateral total joint replacement has been questioned in the literature $[3,4]$.

A previous study compared overall transfusion rates between patients who donated autologous blood and a control group. Autologous blood donation was associated with a significantly higher total number of transfusions ( 0.93 per patient) than control ( 0.33 per patient, $p<0.001)$, as well as a lower allogeneic transfusion rate $(14 \%$ vs. $25 \%, p<0.03)$ [5]. While non-anemic patients displayed almost identical allogeneic transfusion rates regardless of predonation status ( $8 \%$ vs. $9 \%$ ), anemic patients had a higher incidence of allogeneic transfusions if they did not donate autologous blood $(29 \%$ vs. $72 \%, p=0.006)$. The current data indicate that targeting anemic patients for preoperative donation of autologous blood serves to reduce the number of discarded units and improve cost effectiveness. Patients who were enrolled in the targeted donation protocol groups $(\mathrm{A}+\mathrm{C})$ received an average 0.34 units per patient, significantly less than the average 0.93 observed in the previous study when PABD was utilized in all patients. Implementation of target blood management in the private practice environment is possible. However, enrollment in this protocol is largely dependent on the surgeon's dedication to enroll patients. Ideally, preoperative patient screening and autologous blood

Table 2 Transfusion rates for patients who underwent primary total knee arthroplasty

\begin{tabular}{|c|c|c|c|c|c|c|}
\hline Number of TKAs per group & $\begin{array}{l}\text { Patients with } \\
\text { autologous } \\
\text { transfusion }\end{array}$ & $\begin{array}{l}\text { Patients with } \\
\text { allogeneic } \\
\text { transfusion }\end{array}$ & $\begin{array}{l}\text { Total number of } \\
\text { allogeneic units }\end{array}$ & $\begin{array}{l}\text { Average allogeneic } \\
\text { transfusion per patient }\end{array}$ & $\begin{array}{l}\text { Overall transfusion } \\
\text { per patient }\end{array}$ & $\begin{array}{l}\text { Autologous wastage } \\
\text { rate }(\%)\end{array}$ \\
\hline Group A $(n=98)$ & $70(71 \%)$ & $9(9 \%)$ & 12 & 0.12 & 0.84 & 29 \\
\hline Group B $(n=135)$ & 0 & $44(33 \%)$ & 55 & 0.41 & 0.41 & \\
\hline Group C $(n=185)$ & 0 & $11(5.9 \%)$ & 13 & 0.07 & 0.07 & \\
\hline $\begin{array}{l}\text { Patients treated according to } \\
\text { TPABD protocol }(n=283)\end{array}$ & $70(25 \%)$ & $20(7 \%)$ & 25 & 0.08 & 0.34 & 29 \\
\hline
\end{tabular}


donation are handled independently of the surgeon's office to improve enrollment and should be handled by the hospital as part of the routine preoperative medical examination.

This investigation confirms that abandoning PABD for non-anemic patients does not increase allogeneic transfusion risk and significantly decreases the percentage of wasted autologous blood and therefore reduces overall cost. As such, the current study supports the use of targeted autologous blood donation in patients undergoing primary TKA.

Acknowledgments The authors would like to thank Michele Prigo, MA, CHES, Coordinator of the Blood Preservation Center, for her effort in enrolling patients.

\section{Disclosures}

Conflict of Interest: Jad Bou Monsef, MD, Johannes Buckup, MD, and David Mayman, MD have declared that they have no conflict of interest. Amar Ranawat, MD received a grant from Ceramtec, received consulting fee or honoraria from DePuy, Mako, Convatec, Medtronic, and Nova, received payment for work on Speaker Bureau from DePuy and Stryker Ortho Publication: JOA for the study, and payment for lectures including service on speakers bureaus from Depuy and Stryker, royalties from DePuy, Stryker, and Ceremtec, and stock options from Conformis, outside the work. Robert Marx, MD receives royalties for The ACL Solution from Demos Health, outside the work. Friedrich Boettner, MD received consulting fee or honorarium and support for travel to meetings for the study or other purposes from Ethicon, paid consultant for Ethicon and Ortho Development, received research grant from Smith \& Nephew, and receives payment for lectures including service on speakers bureaus from DJ Ortho and patent from Hospital for Special Surgery, outside the work.

Human/Animal Rights: All procedures followed were in accordance with the ethical standards of the responsible committee on human experimentation (institutional and national) and with the Helsinki Declaration of 1975 , as revised in 2008 (5)

Informed Consent: Informed consent was obtained from all patients for being included in the study.

Required Author Forms Disclosure forms provided by the authors are available with the online version of this article.

Open Access This article is distributed under the terms of the Creative Commons Attribution License which permits any use, distribution, and reproduction in any medium, provided the original author(s) and the source are credited.

\section{References}

1. Bern MM, Bierbaum BE, Katz JN, Losina E. Autologous blood donation and subsequent blood use in patients undergoing total knee arthroplasty. Transfus Med. 2006; 16: 313-319.

2. Bierbaum BE, Callaghan JJ, Galante JO, Rubash HE, Tooms RE, Welch RB. An analysis of blood management in patients having a total hip or knee arthroplasty. The Journal of bone and joint surgery. 1999; 81: 2-10. American volume.

3. Billote DB, Glisson SN, Green D, Wixson RL. A prospective, randomized study of preoperative autologous donation for hip replacement surgery. The Journal of bone and joint surgery. 2002; 84-A: 1299-1304. American volume.
4. Boettner F, Altneu EI, Williams BA, Hepinstall M, Sculco TP. Nonanemic patients do not benefit from autologous blood donation before total hip replacement. HSS journal: the musculoskeletal journal of Hospital for Special Surgery. 2010; 6(1): 66-70.

5. Boettner FKS, Altneu E, Bou Monsef J, King E, Sculco T. Nonanemic patients do not benefit from autologous blood donation before total knee replacement. HSS J. 2011; 7(2): 141-144.

6. Carless P, Moxey A, O'Connell D, Henry D. Autologous transfusion techniques: a systematic review of their efficacy. Transfus Med. 2004; 14: 123-144.

7. de Andrade JR, Jove M, Landon G, Frei D, Guilfoyle M, Young DC. Baseline hemoglobin as a predictor of risk of transfusion and response to Epoetin alfa in orthopedic surgery patients. Am J Orthop (Belle Mead NJ). 1996; 25: 533-542.

8. Eder AF, Dy BA, Barton J, Kennedy JM, Benjamin RJ. The American Red Cross Hemovigilance Program: advancing the safety of blood donation and transfusion. Immunohematology/American Red Cross. 2009; 25: 179-185.

9. Forgie MA, Wells PS, Laupacis A, Fergusson D. Preoperative autologous donation decreases allogeneic transfusion but increases exposure to all red blood cell transfusion: results of a meta-analysis. International Study of Perioperative Transfusion (ISPOT) Investigators. Archives of internal medicine. 1998; 158: 610-616.

10. Franchini M, Regis D, Gandini G, Corallo F, de Gironcoli M, Aprili G. Preoperative autologous blood donation in primary total knee arthroplasty: a single-centre experience on 214 consecutive patients. Vox sanguinis. 2006; 90: 191-194.

11. Hatzidakis AM, Mendlick RM, McKillip T, Reddy RL, Garvin KL. Preoperative autologous donation for total joint arthroplasty. An analysis of risk factors for allogenic transfusion. The Journal of bone and joint surgery. 2000; 82: 89-100. American volume.

12. Henry DA, Carless PA, Moxey AJ, O'Connell D, Forgie MA, Wells PS, Fergusson D. Pre-operative autologous donation for minimising perioperative allogeneic blood transfusion. Cochrane Database Syst Rev. 2002:CD003602.

13. Keating EM, Meding JB, Faris PM, Ritter MA. Predictors of transfusion risk in elective knee surgery. Clinical orthopaedics and related research. 1998; 357: 50-59.

14. Kurtz S, Ong K, Lau E, Mowat F, Halpern M. Projections of primary and revision hip and knee arthroplasty in the United States from 2005 to 2030. The Journal of bone and joint surgery American volume. 2007; 89: 780-785.

15. Millett PJ, Porramatikul M, Chen N, Zurakowski D, Warner JJ. Analysis of transfusion predictors in shoulder arthroplasty. The Journal of bone and joint surgery American volume. 2006; 88: 1223-1230.

16. Muller U, Roder C, Pisan M, Orler R, El-Kerdi A, Eggli S. Autologous blood donation in total knee arthroplasties is not necessary. Acta orthopaedica Scandinavica. 2004; 75: 66-70.

17. Munoz M, Garcia-Erce JA, Villar I, Thomas D. Blood conservation strategies in major orthopaedic surgery: efficacy, safety and European regulations. Vox sanguinis. 2009; 96: 1-13.

18. Murphy P, Heal JM, Blumberg N. Infection or suspected infection after hip replacement surgery with autologous or homologous blood transfusions. Transfusion. 1991; 31: 212-217.

19. Rosencher N, Kerkkamp HE, Macheras G, et al. Orthopedic Surgery Transfusion Hemoglobin European Overview (OSTHEO) study: blood management in elective knee and hip arthroplasty in Europe. Transfusion. 2003; 43: 459-469.

20. Salido JA, Marin LA, Gomez LA, Zorrilla P, Martinez C. Preoperative hemoglobin levels and the need for transfusion after prosthetic hip and knee surgery: analysis of predictive factors. The Journal of bone and joint surgery. 2002; 84-A: 216-220. American volume.

21. Shankar NS. Minimally invasive technique in total knee arthroplasty-history, tips, tricks and pitfalls. Injury. 2006; 37(Suppl 5): S25-30.

22. Tobias JD. Strategies for minimizing blood loss in orthopedic surgery. Seminars in hematology. 2004; 41: 145-156.

23. Weber EW, Slappendel R, Prins MH, van der Schaaf DB, Durieux ME, Strumper D. Perioperative blood transfusions and delayed wound healing after hip replacement surgery: effects on duration of hospitalization. Anesthesia and analgesia. 2005; 100: 1416-1421. 